\title{
Ueber den bedeutenden Bromgehalt der Asche des Fucus vesiculosus aus der ostsee, so wie iiber die Entdeckung des Broms neben Jod; von
}

\author{
Th. Marsson, \\ A potheker in Wolgast.
}

Durch die Gite des Herrn Apothekers Schmidt in Altenkirchen auf Rügen erhielt ich eine Quantität Fucusasche, um eine quantitative Bestimmung des darin enthaltenen Jods vorzunehmen. Der Fucus vesiculosus findet sich an den nördlichen Küsten der Insel Rügen in so grosser Menge, dass er dort als ein schätzbarer Dünger für die Aecker benutzt wird, und es leicht ist, sich dort bedeutende Quantitäten Asche zu verschaffen.

Die zur Untersuchang verwendete Asche enthielt noch etwas Kohle und Sand, so wie einige Bruchstückchen von Muscheln, die bäufig sehr fest an dem Fucus anbängen. Die wässerige Lösung der Asche enthielt kein kohlensaures Natron, aber Kalkerde, Magnesia, Schwefelsäure und viel Kochsalz; mit Chlorwasser und Stärke zeigte sich eine

merksam zu machen. Der Beutel sammt dem grossen Stück anhängender Bauchhaut wog $7 \frac{1}{2}$ Drachmen. Das Gewicht des Bleies hetrug etwas mehr als $1 \frac{1}{2}$ Drachmen und das des Mloschus nicht ganz 2 Drachmen. Ich will nachträglich hinzufügen, dass auch in dieser Moschusmasse erbsengrosse Kugeln enthalten waren, die sich übrigens als ächter Joschus verhielten. Da auch Andere, z. B. Geiger anfübren, dass die Moschusmasse manchinal in kugeligen Klümpchen sich darstelle, (S. Pharmacopoeae universal. p.183: Moschus ipse...massa est grumosa et granulosa... glebulis globosis vel oblongis variae magnitudinis...plus minus intermixta...), so habe ich damals auch keinen besondern Werth auf jene kugelförmige Zusammenballung des Moschus gelegt. Indessen wäre doch möglich, dass sie durch das metallische Blei befördert würde, was denn durch die obige Mittheilung des Hrn.La ux wahrscheinlich gemacht werden könnte. Dass aber der tunguinische oder chinesische Hoschus ein durch Kunst parliell veründerles Naturproduct sci, wie Goebel angiebt (S. dies. Arch. Bd. 35. p.329.), bedarf wohl sẹhr der Bestätigung.

H. Wr. 
deutliche Jodreaction, die bei weiterem Zusatze von Chlorwasser einer intensiven Bromreaction Platz machte, so dass die Menge des Broms bedeutend vorzuwalten schien. Da meines Wissens die Quantität beider Körper in einem Kelp der Ostsee bis jetzt nicht bekannt ist, schien mir die Bestimmung nicht ohne Interesse

500 Gramm Asche wurden durch wiederholte I) igestion mit heissem Wasser im Wasserbade erschöplt. aus der wässerigen Lösung durch kohlensaures Natrum die Erden gefällt, und die abfiltrirte Flüssigkeit zur Krystallisation verdampft. Die von den Krystallen abgegossene Mutterlauge wurde dann, nachdem stets die Krystalle mit wenig Wasser abgespült waren, wiederholt eingedampft und krystallisirt. Die letzle Mutterlauge liess ich im Wasserhade möglichst eintrocknen und kochte sie mehrere Male mil Alkohol aus. Von der alkoholischen Auflüsung wurde der Alkohol verdunstet und die Salzmasse wieder in Wasser aufgelöst und filtrirt.

Zur Bestimmung des Jods fällte ich die wässerige, neutrale Lösung mit Palladiumchlorür, bis keine Trübung mehr erfolgte, sonderte den schwarzen Niederschlag, nachlem er sich vollständig abgelagert hatte, durch ein zuvor bei $70^{\circ} \mathrm{C}$. getrocknetes und gewogenes Filter, wusch den Niederschlag zuerst mit Wasser, hernach mit Alkohol vollständig aus und trocknete wieder bei $70^{\circ} \mathrm{C}$. bis keine Gewichtsabnahme bemerklich war.

Es wurden 0,221 Grm. Jodpalladium entsprechend $0,155 \mathrm{Grm}$. Jod erhalten.

Von der Waschflüssigkeit, deren Gewicht $101 \mathrm{Grm}$ betrug, wurde nur ein Theil 38,1 Grm. mit salpetersaurem Silberoxyd gefällt, und der Niederschlag, nachdem er durch Decantation vollständig ausgewaschen war, in einen Porcellantiegel gespuilt, darin getrocknet und geschmolzen. Erhalten waren 6,801 Grm. Chlorbromsilber.

Zur Bestimmung des Broms in dem Chlorbromsilber bediente ich mich der indirecten Methode, indem uiber die in einer Kugelröhre geschmolzene Silberverbindung ein Strom von trocknem Chlorgase geleitet wurde, bis 
Bromgehall der Asche des Fucus vesiculos. aus der Ostsee. 283

alles Brom ausgetrieben war, und zwei Wägungen übereinstimmten.

In zwei Versuchen gaben

Chlorhromsilber.

Chlorsilber. Gewichtsdifferenz.

1) 0,7125 Grm. $\quad 0,637$ Grm. 0,0755 Grm.

2) $1,68.5 \% 1,152 \% 0,1375 \%$

lis berechnel sich hieraus das Bromsilber und Brom nach der Proportion: die Differenz zwischen dem Atomgewicht des Chlorsilbers und Bromsilbers verhält sich zum Atomgewicht des Bromsilbers, wie die erhaltene Gewichtsabnahme zu $\mathrm{x}$. Bei der Berechnung wurden dic neuen Atomgewichte des Bromsilbers 188 und des Chlorsilbers 143,40 zu Grunde gelegt.

Für die beiden Versuche erhält man nach der Formel:

1) $\mathrm{x}=\frac{188 \cdot 0,0755}{44,54}=0,3187 \mathrm{Br} \mathrm{Ag}=0,1356 \mathrm{Br}$

2) $x=\frac{188 \cdot 0,1375}{44,54}=0,5804 \mathrm{Br} \mathrm{Ag}=0,2469 \mathrm{Br}$

oder aul 100 Theile

$$
\begin{array}{cc}
1 . & 2 . \\
19,03 & 19,15 \text { Brom. }
\end{array}
$$

Es gaben aber vorhin $38,1 \mathrm{Grm}$. der Waschflissigkeit 6,801 Grm. Chlorbromsilber, mithin gaben $101 \mathrm{Grm}$. oder die ganze Flüssigkeit 18,03 Grm. Chlorbromsilber, welche wieder 19,09 Proc. Brom enthalten, entsprechend 3,420 Grm.

Es sind hiernach in der Fucusasche auf 0,155 Grm. Jod 3,42 Grm Brom enthalten, was $22 \mathrm{mal}$ so viel Brom als jod beträgt, oder es enthalten

$$
\begin{gathered}
100 \text { Th. Asche } \\
0,031 \text { "Jod } \\
0,682 \text { "Brom. }
\end{gathered}
$$

So leicht die Entdeckung des Jods oder Broms in eincr Fliissigkeit ist, wenn nur einer von beiden Körpern darin enthalten ist, so umständlich kann die Lntersuchung werden, wenn beide zusammen vorkommen. Man war genöthigt, erst das Jod aus der Flussigkeit zu entfernen, um das Brom durch Chlor abscheiden und durch Aether aufnehmen zu können. Man pflegte das Jod als Kupferjodiur durch eine Lösung von schwefelsaurem Eisenoxydul 
284 Bromgehall der Asche des Fucus vesiculos. aus der Ostsee.

und Kupferoxyd zu fällen, doch ist diese Fällung keineswegs vollständig; anderntheils hat man der Flüssigkeit Eisen zugesetzt, dessen Anwesenheit wiederum die Ursache von Täuschungen sein kann, wenn es nicht auch wieder aus der Fliissigkeit entfernt wird.

Ich machte die Bemerkung, dass das Brom, wenn es neben Jod vorkommt, auf eine viel einfachere Weise gleichfalls durch Chlor nachzuweisen ist.

Vermuthet man also in einer Flüssigkeit Jod und Brom, so setzt man, wenn die Flüssigkeit alkalisch sein sollte, einige Tropfen Salzsäure hinzu, darauf' etwas dünnen recht gleichmässigen Stärkekleister, und tropfenweise schwaches Chlorwasser bis die Jodreaction eintritt. Man fährt dann mit dem Zusatz von Chlorwasser fort. Ist nun Jod allein vorhanden, so geht die intensiv indigblaue Farbe der Stärke allmälig in eine weinrothe über, welche Farbe immer heller roth wird, bis die Stärke entfärbt ist und bei weiterem Zusatz von Chlorwasser keine gelbe Färbung eintritt. Geht aber die blaue Farbe der Jodstärke bei weiterem Zusalze des Chlorwassers nicht ins Weinrothe über, sondern ins Bräunliche, ins Orange und zuletzt ins Gelbe, so kann man sicher auf die Gegenwart von Brom schliessen. Es beruht diese Reaction einfach darauf, dass das Chlor die Jodverbindung früher zersetzt, als die Bromverbindung, und erst wenn das Jod der Jodstärke in Chlorjod verwandelt ist, wirkt das Chlor auf die Bromverbindung zersetzend ein, und die orange Slärke, die jelzt entstebt, ist eine Verbindung von Bromstärke mit Jod oder mit Chlorjod. Dass die Stärke nicht reine Bromstärke ist, folgt aus dem Verhalten einer jodfreien Bromkaliumlösung, die bei gleichem Bromgehalt mit Chlor nur eine schwache gelbe Farbe annimmt, während bei Gegenwart von Jod die Stärke viel dunkler und orange gefärbt wird. Man kann auf diese Weise noch करणें Brom in einer Flüssigkeit neben Jod nachweisen, wenn letzteres in nicht zu grosser Menge vorwaltet, während eine reine Bromkaliumlösung von dieser Verdünnung durch Chlor und Stärke kaum gelb gefärbt wird. Ist die Quantität 
des Jods nur sehr klein, die des Broms aber bedeutend überwiegend, so kann man beim vorsichtigen Zusalz von Chlorwasser die Flüssigkeit vollständig entfärben, bevor die intensiv orange Reaction auf Brom eintritt. Der zu diesem Versuche verwandte Kleister muss aber durchaus gleichmässig und nicht klümperig sein, weil die Klïmpchen durch das Chlor ihre Farbe nur schwer verlieren. $1 \mathrm{Th}$. Stärke auf $50 \mathrm{Th}$. Wasser giebt einen dünnen gleichmässigen Kleister, der sich zu diesen Versuchen besonders gut eignet.

\section{Ueber die Zusammensetzung der Aschen der Rapskörner und des Rapsstrohes; von W. Baer, d. Z. zu Berlin. (Dritter Beitrag zur Agricullurchemie.)}

Auch von der Erndie des Jahres (1849) wurden mir zwei Sorten des Samens von Brassica napus oleifera (Sommerraps) mit dem dazu gehörigen Stroh von verschiedenen Standorten zur Untersuchung der Aschen ubergeben. Den Gang der Untersuchung habe ich bereits in dies. Arch. II. Reihe Bd. 57 pag. 138 und Bd. 61 pap. 267 ausführlich mitgetheill; deshalb beschränke ich mich hier darauf, nur die Resultate der Analysen mitzutheilen, so wie einige Abänderungen, die eingetreten sind, kurz anzuführen.

Obgleich ich auf das Aussuchen der zur Analyse bestimmten Körner die grösste Sorgfalt verwendet hatte, so war es mir doch nicht gelungen, alle fremdartigen Theile zu entfernen. In der Asche fanden sich beim Auflösen derselben in Chlorwasserstoffsäure kleine runde Steinchen von der Grösse der Rapskörner, die offenbar eben wegen gleicher Grösse und Farbe mit diesen nicht hatten davon unterschieden werden können. Um bei den ferneren Analysen diesem "Uebelstande zu begegnen, wurden die Körner mit destillirtem Wasser geschlämmt, dann rasch mit 